\title{
ASYMPTOMATIC BACTERIURIA AMONG PREGNANT WOMEN ATTENDING A TERTIARY CARE HOSPITAL IN WESTERN NEPAL: A CROSS-SECTIONAL PROSPECTIVE STUDY
}

\author{
Shristi Raut, ${ }^{1}$ Sulochana Khatiwada, ${ }^{1}$ Narayan GC $^{2}$
}

\begin{abstract}
INTRODUCTION

Urinary tract of female undergoes tremendous changes during pregnancy which increases their risk of acquiring infection. Asymptomatic bacteriuria is a common entity among pregnant women which refers to significant bacteriuria $\left(>10^{5}\right.$ bacteria per $\mathrm{ml}$ of urine) without any typical symptoms of urinary tract infection. Asymptomatic bacteriuria can lead to various maternal and fetal complications if not detected and treated on time.
\end{abstract}

\section{MATERIAL AND METHODS}

Total 280 urine samples were collected in sterile universal containers from pregnant women not showing typical symptoms of urinary tract infection at the time of sample collection. Urine samples were inoculated in both MacConkey agar and Blood agar by semi quantitative culture method. Culture plates were reported after 24 hours of incubation at $37^{\circ} \mathrm{C}$. Bacteria isolated were subjected to antibacterial susceptibility testing by modified Kirby-Bauer disc diffusion method.

\section{RESULTS}

Out of 280 urine cultures, 213 samples were sterile. Significant bacteriuria was seen in 25 cases (8.9\%) followed by insignificant bacteriuria $(20,7.14 \%)$ and contamination $(17,6.10 \%)$. Highest number of cultures positive were in age group 21-30 years $(19,9.1 \%)$. Out of 25 cases of significant bacteriuria, $60 \%$ were primigravida and $40 \%$ were multigravida. The most common organism isolated was Escherichia coli (10, 40\%) followed by Klebsiella pneumoniae $(5,20 \%)$.

\section{CONCLUSION}

Screening of all pregnant women for asymptomatic bacteriuria is essential during their antenatal checkup. Escherichia coli is the commonest organism that cause asymptomatic bacteriuria. Appropriate antibiotic therapy is absolutely necessary for positive cases on the basis of antimicrobial susceptibility test result to prevent unwanted obstetric complications.

\section{KEYWORDS}

Asymptomatic bacteriuria, Escherichia coli, Pregnant women, Urinary tract infection.

1. Department of Microbiology, Universal College of Medical Sciences, Bhairahawa, Nepal

2. Department of Gynecology and Obstetrics, Universal College of Medical Sciences, Bhairahawa, Nepal

DOI: http//doi.org/10.3126/jucms.v9i01.37973

For Correspondence
Dr. Shristi Raut
Department of Microbiology
Universal College of Medical Sciences
Bhairahawa, Nepal
Email:rautshristi@gmail.com




\section{INTRODUCTION}

Bacteriuria is the presence of bacteria in urine which can be either symptomatic or asymptomatic. There is continuous multiplication and activity of bacteria in urinary tract even in asymptomatic cases of bacteriuria. Presence of $\geq 10^{5}$ colony forming unit (CFU) or bacteria per ml of freshly passed midstream clean-catch urine with no typical symptoms (urgency, burning micturition, dysuria, foul smell and altered color of urine) of urinary tract infection is known as asymptomatic bacteriuria (ASB). ${ }^{1}$ ASB is common among pregnant women and often associated with adverse maternal and fetal outcome such as acute pyelonephritis, preterm labor and low birth weight fetus. $^{2-4}$

Urinary tract of women undergoes profound physiological and anatomical changes during pregnancy that contribute to the higher risk of infection. ${ }^{5}$ Dilatation of ureters and renal calyces occurs as progesterone causes relaxation of smooth muscles. In addition, when gravid uterus compresses ureters and urinary bladder, vesicoureteral reflux may occur. All these factors collectively contribute to increasing the risk of urinary tract infection in pregnancy. Female urethra being short and in close proximity to anus, gastrointestinal flora easily get access to urinary tract and cause infection. Thus, pregnant women are at high risk of both symptomatic and asymptomatic urinary tract infection. Moreover, as patients do not show symptoms in ASB, cases do not seek medical advice and remain undiagnosed. Regular screening of pregnant women is essential to detect ASB. Previous studies have demonstrated factors like low socioeconomic status, high parity and informal settlement as important risk factors for asymptomatic bacteriuria.,

ASB is the most significant factor predisposing pregnant women to symptomatic bacteriuria and eventually pyelonephritis. Culture of freshly passed mid-stream clean-catch urine is the most sensitive and standard method to detect ASB in pregnant women. Cases of ASB with significant colony count $\left(10^{5} \mathrm{CFU} / \mathrm{ml}\right.$ of urine) need treatment with antibiotic to prevent further complications. Precise antibiotic treatment on the basis of antibacterial susceptibility report may be associated with a reduction in the cases of preterm and low birth weight newborns. Antibiotic therapy can also reduce persistent bacteriuria at the time of delivery.

The high prevalence of ASB among pregnant women and its probable harmful consequences to mother and baby demands timely screening and treatment of the positive cases. However, the actual scenario of ASB during pregnancy in different parts of Nepal is not known which is evidenced by the paucity of the literature on this topic. This study takes an opportunity to investigate ASB in pregnant women in Western Nepal in regards to its prevalence, demographic profile of the participants, the common microbiological isolates responsible for, their antibiotic profile and drug resistance pattern.

\section{MATERIAL AND METHODS}

This study was a cross-sectional prospective study conducted in a tertiary care hospital in Western part of Nepal with the help of preformed questionnaires and laboratory analysis of urine samples obtained from pregnant women visiting outpatient department of Gynecology for routine antenatal checkup. Total 280 urine samples were collected in sterile universal containers from pregnant women who showed no any apparent signs of urinary tract infection at the time of sample collection. The study was conducted for a time period of six months from June to December 2019.

Pregnant women were interviewed using the questionnaires in the Performa before collection of urine. Samples were sent to Microbiology Laboratory immediately after collection. Urine samples were inoculated in both MacConkey agar and Blood agar by semi quantitative culture method. Culture plates were reported after 24 hours of incubation at $37^{\circ} \mathrm{C}$. Both culture plates were observed for confluent growth or significant bacteriuria. Significant bacteriuria was considered when colony count of the bacteria grown in culture plate was $\geq 10^{5}$ CFU per $\mathrm{ml}$ of urine. Colony count less than that was considered as insignificant bacteriuria. When more than three types of bacteria were observed in culture plate and when commensals of urinary tract were noted, such cases were reported as contamination. Pure colonies from significant bacteriuria cases were subjected to Gram staining. Subsequently, suitable biochemical tests were performed and isolates were subjected to antibacterial susceptibility testing by modified Kirby-Bauer disc diffusion method in Mueller Hinton agar (MHA). The antibiotic disc selected for Gram negative bacteria were ampicillin $(10 \mu \mathrm{g})$, amoxiclav $(20 / 10$ $\mu \mathrm{g})$, amikacin $(30 \mu \mathrm{g})$, cotrimoxazole $(1.25 / 23.75 \mu \mathrm{g})$, norfloxacin $(10 \mu \mathrm{g})$, nitrofurantoin $(300 \mu \mathrm{g})$, ceftriaxone (30 $\mu \mathrm{g})$, ciprofloxacin $(5 \mu \mathrm{g})$, cefuroxime $(30 \mu \mathrm{g})$ and imipenem $(10 \mu \mathrm{g})$.

For Pseudomonas aeruginosa, additional antibiotics such as piperacillin $(100 \mu \mathrm{g})$, carbenicillin $(100 \mu \mathrm{g})$, ceftazidime (30 $\mu \mathrm{g})$, colistin $(10 \mu \mathrm{g})$ and polymyxin B (300 units) were selected. Antibiotics such as penicillin G (10 units) and vancomycin $(30 \mu \mathrm{g})$ were added for Gram positive bacteria. All these antibiotics were selected and their susceptibility pattern were reported as per the guidelines of CLSI (2018). ${ }^{6}$ Antibiotic discs were bought from HiMedia diagnostic laboratory, Mumbai, India. For antibacterial susceptibility testing, antibiotic discs were placed on MHA maintaining 25 $\mathrm{mm}$ distance between two discs, incubated at $37^{\circ} \mathrm{C}$ for $18-24$ hours. Next morning, zone of inhibition was measured for 
each antibiotic and results were interpreted according to CLSI guidelines as sensitive or resistant. Obtained data were entered in Microsoft excel software first and then transferred to SPSS 21 version for statistical analysis.

\section{RESULTS}

Total 280 samples were collected from pregnant women visiting Gynecology outpatient department for regular antenatal checkup with no any typical symptoms of urinary tract infection. There was no growth in 218 samples out of 280 (77.85\%) urine culture. Significant bacteriuria was seen in 25 cases $(8.9 \%)$ followed by insignificant bacteriuria $(20,7.14 \%)$ and contamination $(17,6.10 \%)$ [Table 1$]$.

\section{Table 1. Results of urine culture of pregnant women}

\begin{tabular}{lcc}
\hline Culture result & Number of cases & Percentage \\
\hline Significant bacteriuria & 25 & $8.90 \%$ \\
Insignificant bacteriuria & 20 & $7.14 \%$ \\
Contamination & 17 & $6.10 \%$ \\
Sterile & 218 & $77.85 \%$ \\
Total & 280 & $100 \%$ \\
\hline
\end{tabular}

Highest number of cultures positive cases were observed in age group 21-30 years $(76 \%, 19 / 25)$. Out of 25 cases of significant bacteriuria, $60 \%$ were primigravida and $40 \%$ were multigravida [Table 2].

Table 2. Distribution of culture positive cases with respect to age and parity

\begin{tabular}{lcc}
\hline Age group & $\begin{array}{c}\text { Culture positive } \\
(\mathrm{n} / \%)\end{array}$ & $\begin{array}{c}\text { Culture negative } \\
(\mathrm{n} / \%)\end{array}$ \\
\hline$<20$ years & $0(0 \%)$ & $13(5.1 \%)$ \\
$21-30$ years & $19(76 \%)$ & $190(74.5 \%)$ \\
$31-40$ years & $6(24 \%)$ & $46(18.0 \%)$ \\
$>40$ years & $0(0 \%)$ & $6(2.4 \%)$ \\
Parity & & \\
Primigravida & $15(60 \%)$ & $163(63.9 \%)$ \\
Multigravida & $10(40 \%)$ & $92(36.1 \%)$ \\
Total & $25(100 \%)$ & $255(100 \%)$ \\
\hline
\end{tabular}

The most common organism isolated was Escherichia coli (10, 40\%) followed by Klebsiella pneumoniae (5, 20\%) [Table 3]. Gram positive bacteria were also isolated but comparatively less in number than Gram negative bacteria. Staphylococcus aureus $(3,12 \%)$ was the commonest organism isolated among Gram positive bacteria.
Table 3. Distribution of bacterial isolates in culture positive cases

\begin{tabular}{lcc}
\hline Bacterial isolates & Number of cases & Percentage \\
\hline Escherichia coli & 10 & $40 \%$ \\
Klebsiella pneumoniae & 5 & $20 \%$ \\
Pseudomonas aeruginosa & 3 & $12 \%$ \\
Staphylococcus aureus & 3 & $12 \%$ \\
Enterococcus spp & 2 & $8 \%$ \\
Proteus mirabilis & 1 & $4 \%$ \\
Streptococcus agalactiae & 1 & $4 \%$ \\
\hline Total & 25 & $100 \%$ \\
\hline
\end{tabular}

Both Escherichia coli and Klebsiella pneumoniae were 100\% sensitive to imipenem and $100 \%$ resistant to ampicillin. Escherichia coli were highly sensitive to ciprofloxacin (90\%), nitrofurantoin $(90 \%)$, amikacin $(80 \%)$, ceftriaxone $(70 \%)$, amoxiclav (60\%) and norfloxacin $(60 \%)$ whereas less sensitive to cotrimoxazole $(50 \%)$ and cefuroxime (40\%). Similarly, Klebsiella pneumoniae showed high sensitivity to amikacin $(100 \%)$, norfloxacin $(100 \%)$, nitrofurantoin $(100 \%)$, ciprofloxacin $(100 \%)$, ceftriaxone $(100 \%)$, cotrimoxazole $(80 \%)$, amoxiclav $(60 \%)$ and cefuroxime (60\%). Among Gram positive bacteria, Staphylococcus aureus was the commonest isolate which was $100 \%$ sensitive to amikacin, ciprofloxacin, nitrofurantoin and vancomycin. Sensitivity to cotrimoxazole and ceftriaxone was $66.6 \%$ whereas sensitivity to norfloxacin, cefuroxime and penicillin was 33.3\% [Table 4].

Table 4. Antimicrobial susceptibility pattern of the isolated organisms

\begin{tabular}{|c|c|c|c|c|c|c|c|}
\hline Antibiotics & $\begin{array}{l}\text { E. coli } \\
\text { n (\%) }\end{array}$ & $\begin{array}{l}\text { K. } \\
\text { pneumoniae } \\
\text { n }(\%)\end{array}$ & $\begin{array}{l}P \\
\text { aeruginosa } \\
\mathrm{n}(\%)\end{array}$ & $\begin{array}{l}P P \\
\begin{array}{l}P \text { mirabilis } \\
\text { n }(\%)\end{array}\end{array}$ & $\begin{array}{l}\text { S. aureus } \\
\text { n }(\%)\end{array}$ & $\begin{array}{l}\text { Enterococc } \\
\text { us spp } \\
\mathrm{n}(\%)\end{array}$ & $\begin{array}{l}\text { S. } \\
\text { agalactiae } \\
\mathrm{n}(\%)\end{array}$ \\
\hline AMP & $0(0 \%)$ & $0(0 \%)$ & $0(0 \%)$ & $1(100 \%)$ & ND & ND & ND \\
\hline $\mathrm{AMC}$ & $6(60 \%)$ & $3(60 \%)$ & $1(33.3 \%)$ & $1(100 \%)$ & ND & ND & ND \\
\hline AK & $8(80 \%)$ & $5(100 \%)$ & $3(100 \%)$ & $1(100 \%)$ & $3(100 \%)$ & $2(100 \%)$ & $1(100 \%)$ \\
\hline $\mathrm{NX}$ & $6(60 \%)$ & $5(100 \%)$ & $3(100 \%)$ & $1(100 \%)$ & $1(33.3 \%)$ & $0(0 \%)$ & $1(100 \%)$ \\
\hline CIP & $9(90 \%)$ & $5(100 \%)$ & $3(100 \%)$ & $1(100 \%)$ & $3(100 \%)$ & $2(100 \%)$ & $1(100 \%)$ \\
\hline NIT & $9(90 \%)$ & $5(100 \%)$ & $2(66.6 \%)$ & $1(100 \%)$ & $3(100 \%)$ & $2(100 \%)$ & $1(100 \%)$ \\
\hline COT & $5(50 \%)$ & $4(80 \%)$ & $3(100 \%)$ & $1(100 \%)$ & $2(66.6 \%)$ & $2(100 \%)$ & $1(100 \%)$ \\
\hline CTR & $7(70 \%)$ & $5(100 \%)$ & $3(100 \%)$ & $1(100 \%)$ & $2(66.6 \%)$ & $2(100 \%)$ & $1(100 \%)$ \\
\hline CAZ & ND & ND & $3(100 \%)$ & ND & ND & ND & ND \\
\hline PI & ND & ND & $2(66.6 \%)$ & ND & ND & ND & ND \\
\hline $\mathrm{CB}$ & ND & ND & $2(66.6 \%)$ & ND & ND & ND & ND \\
\hline $\mathrm{CL}$ & ND & ND & $3(100 \%)$ & ND & ND & ND & ND \\
\hline PB & ND & ND & $3(100 \%)$ & ND & ND & ND & ND \\
\hline CFM & $4(40 \%)$ & $3(60 \%)$ & $1(33.3 \%)$ & $0(100)$ & $1(33.3 \%)$ & $0(0 \%)$ & $1(100)$ \\
\hline IPM & $10(100 \%)$ & $5(100 \%)$ & $3(100 \%)$ & $1(100 \%)$ & ND & ND & ND \\
\hline P & ND & ND & ND & ND & $1(33.3 \%)$ & $1(50 \%)$ & $1(100 \%)$ \\
\hline VA & ND & ND & ND & ND & $3(100 \%)$ & $2(100 \%)$ & $1(100 \%)$ \\
\hline
\end{tabular}

\section{DISCUSSION}

Pregnant women with asymptomatic bacteriuria have increased risk to suffer from symptomatic urinary tract 
infection and various obstetric complications later. ${ }^{7}$ Timely screening and treating ASB with appropriate antibiotic has become a new protocol of a standard care of pregnant women. Along with other routine investigations during regular antenatal visits, culture of urine is essential for the pregnant women even when they do not have urinary problems.

Asymptomatic cases of significant bacteriuria more than $1,00,000 \mathrm{bacteria} / \mathrm{ml}$ of urine was only considered as asymptomatic bacteriuria (ASB) among pregnant women in this study. The rate of ASB detected by this study was $8.9 \%$ which is higher than $7.3 \%$ reported by a study in India and lower than $10 \%$ reported from Egypt. ${ }^{8,9}$ Some studies reported higher prevalence rate of ASB up to $45.3 \%{ }^{10}$ Within Nepal, Neupane et al reported $26 \%$ of ASB from Chitwan. ${ }^{11}$ These huge variations in prevalence of ASB from place to place may be associated with environmental conditions, socioeconomic status, personal hygiene, education level, number of pregnancies, maternal age, religious beliefs and sexual behavior of the study population.

Highest number of cultures positive cases were in age group $21-30$ years $(76 \%, 19 / 25)$. Out of 25 cases of significant bacteriuria, $60 \%$ were primigravida and $40 \%$ were multigravida. These findings are consistent with the results of a study by Sujatha $\mathrm{R}$ et al where as another study in Yemen reported a highest prevalence of ASB among 35-39 years of pregnant women. ${ }^{8,12}$ Women in different countries prefer different part of their reproductive age to start family. In this study, maximum pregnant women $(74.6 \%, 209 / 280)$ were in the age group 21-30 years and maximum ASB was also seen in the same group.

The most common organism isolated was Escherichia coli $(10,40 \%)$ followed by Klebsiella pneumoniae $(5,20 \%)$ in this study. Escherichia coli is the normal flora of gastrointestinal tract which can easily get access to urinary tract because of their close proximity in female. In pregnant women also, Escherichia coli is the predominant organism to cause ASB which is evidenced by many studies. ${ }^{8,13-16}$ Escherichia coli was $100 \%$ sensitive to imipenem and $100 \%$ resistant to ampicillin. Escherichia coli were highly sensitive to ciprofloxacin, nitrofurantoin, amikacin, ceftriaxone, amoxiclav and norfloxacin whereas less sensitive to cotrimoxazole and cefuroxime. Only $24 \%$ of the causative organisms of ASB were Gram positive bacteria. The commonest organism among Gram positive bacteria was Staphylococcus aureus. Some studies reported Gram positive bacteria as the commonest cause of ASB. ${ }^{17,18}$ A study in Iran reported $16.8 \%$ of coagulase-negative staphylococci as a cause of ASB. ${ }^{17}$ Other studies also reported coagulase-negative staphylococci as an important cause of ASB. ${ }^{18}$

Common organisms causing ASB such as Escherichia coli and Klebsiella pneumoniae showed high sensitivity to amikacin, norfloxacin, nitrofurantoin, ciprofloxacin, ceftriaxone and imipenem. Same results were observed in various other studies. ${ }^{8,10}$ A study recommended Fosfomycin as an important drug to treat ASB in pregnant women considering its high sensitivity, convenient route of administration and safe nature. ${ }^{7}$ Microorganisms are evolving day by day and becoming resistant to commonly used drugs. Irrational use of antibiotics that includes availability of the drugs over the counter without the prescription by physician and not considering culture and sensitivity reports are the major factors for the emergence of drug resistant strains of bacteria. $^{19,20}$ The knowledge of the common pathogens that cause ASB in a particular population and their antimicrobial susceptibility pattern is irreplaceable for reducing maternal and fetal morbidity and mortality by ASB. In addition, teaching pregnant women to maintain personal hygiene and cleanliness of area around urogenital organ and anus helps to reduce the contamination of urinary tract by gastrointestinal flora.

\section{LIMITATION}

Sample size and duration of this study were less. Extending the duration of the study and increasing the sample size will add value to this study. Number of microorganisms isolated from urine cultures were few. So, the antimicrobial susceptibility test report of each bacterium may not echo with the antibiogram of the bacteria in general.

\section{CONCLUSION}

Asymptomatic bacteriuria is common among pregnant women. Periodic screening of all pregnant women by urine culture for asymptomatic bacteriuria is essential along with other routine laboratory investigations during their antenatal checkup. Asymptomatic bacteriuria can progress to symptomatic cases and lead to maternal and fetal complications in pregnancy. Appropriate antibiotic therapy is absolutely necessary for asymptomatic bacteriuria to prevent these consequences.

\section{CONFLICT OF INTEREST}

\section{None}

\section{ACKNOWLEDGEMENT}

We would like to express our heartfelt gratitude to all the participating pregnant women who provided their urine sample for this study. 


\section{REFERENCES}

1. Smaill FM, Vazquez JC. Antibiotics for asymptomatic bacteriuria in pregnancy. Cochrane Database of Systematic Reviews. 2019;11:1-52.Art No:CD000490.

2. Bookallil M, Chalmers E. Andrew B. Challenges in preventing pyelonephritis in pregnant women in Indigenous communities. Rural Remote Health. 2005;5(3):395.

3. Mignini L, Carroli G, Abalos E, Widmer M, Amigot S, Nardin $\mathrm{JM}$, et al. Accuracy of diagnostic tests to detect asymptomatic bacteriuria during pregnancy. Obstet Gynecol. 2009;113 (2):346-52.

4. Schnarr J, Smaill F. Asymptomatic bacteriuria and symptomatic urinary tract infections in pregnancy. Eur J Clin Invest. 2008;38(2):50-57.

5. Jayalakshmi J, Jayaram VS. Evaluation of various screening tests to detect asymptomatic bacteriuria in pregnant women. Indian J Pathol Microbiol. 2008;51(3):379-81.

6. Humphries RM, Ambler J, Mitchell SL, Castanheira M, Dingle T, Hindler JA, Koeth L, Sei K, on behalf of the CLSI Methods Development and Standardization Working Group of the Subcommittee on Antimicrobial Susceptibility Testing. 2018. CLSI Methods Development and Standardization Working Group best practices for evaluation of antimicrobial susceptibility tests. J Clin Microbiol 56:e01934-17.

7. Celen S, Oruc AS, Karayalcin R, Saygan S, Unlu S, Polat B, Danisman N. Asymptomatic bacteriuria and antibacterial susceptibility patterns in an obstetric population. ISRN Obstet Gynaecol. 2011;2011. Article ID 721872.

8. Sujatha R. Prevalence of Asymptomatic bacteriuria and its antibacterial susceptibility pattern among pregnant women attending the antenatal clinic at Kanpur, India. J Clin Diagn Res. 2014; 8(4):01-03.

9. Abdel-Aziz Elzayat M, Barnett-Vanes A, Dabour MF, Cheng F. Prevalence of undiagnosed asymptomatic bacteriuria and associated risk factors during pregnancy: a cross-sectional study at two tertiary centres in Cairo, Egypt. BMJ Open. 2017;7(3):e013198.

10. Imade PE, Izekor PE, Eghafona NO, Enabulele OI, Ophori E. Asymptomatic bacteriuria among pregnant women. N Am J Med Sci. 2010;2(6):263-6.

11. Neupane MS, Dhakal KS, Neupane HC, Adhikari S, Aryal B. Asymptomatic bacteriuria among pregnant women attending the outpatient clinics of Chitwan Medical College Teaching Hospital in Chitwan, Nepal. Int Res J Pham. 2012;3(11):78-80.

12. Alghalibi SM, Al-Jaufy A, Al-Moayad E. Bacterial urinary tract infection among pregnant women in Sana'a City-Yemen. Arab Gulf Journal of Scientific Research. 2007;25:23-31.

13. Khan S, Singh P, Siddiqui Z, et al. Pregnancy-associated asymptomatic bacteriuria and drug resistance. J Taibah Univ Med Sci. 2015;10:340-5.
14. Olamijulo JA, Adewale CO, Olaleye O. Asymptomatic bacteriuria among antenatal women in Lagos. J Obstet Gynaecol. 2016 Aug;36(6):722-25.

15. Khattak AM, Khattak S, Khan H, Ashiq B, Mohammad D, Rafiq M. Prevalence of asymptomatic bacteriuria in pregnant women. Pak J Med Sci. 2006;22:162-6.

16. Jain V, Das V, Agarwal A, Pandey A. Asymptomatic bacteriuria and obstetric outcome following treatment in early versus late pregnancy in North Indian women. Indian J Med Res. 2013;137(4):753-8.

17. Enayat K, Fariba F, Bahram N. Asymptomatic bacteriuria among pregnant women referred to outpatient clinics in Sanandaj, Iran. Int Braz J Urol. 2008 Nov-Dec;34(6):699-704.

18. Chandel R, Kanga A, Thakur K, Mokta KK, Sood A, Chauhan S. Prevalence of pregnancy associated asymptomatic bacteriuria: A study done in a tertiary care hospital. J Obstet Gynaecol India. 2012;62(5):511-4.

19. Pokharel S, Raut S, Adhikari B. Tackling antimicrobial resistance in low-income and middle-income countries. BMJ Glob Health. 2019;4(6):e002104.

20. Adhikari B, Pokharel S, Raut S, et al. Why do people purchase arrtibiotics over the counter? A qualitative study with patients, climcians and dispensers in Central Eastern and Western Nepal. BMJ Glob Health. 2021;6(5):e005829. 